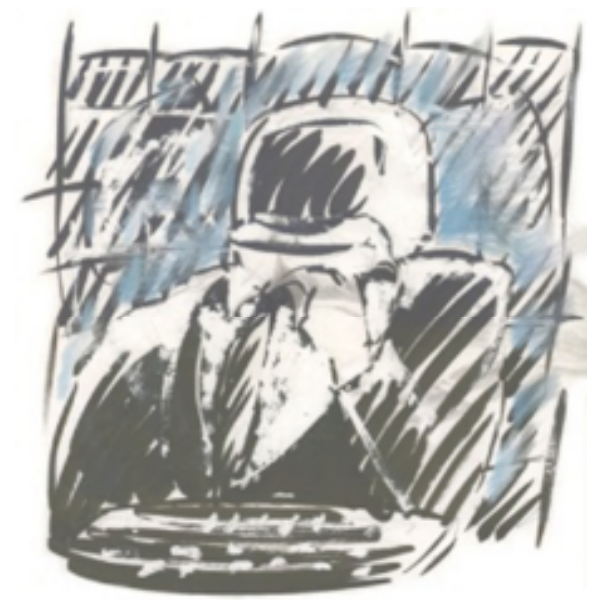

Ilustração Conceição Bicalho

\title{
Aprendendo a ler a televisão: uma confluência possível
}

\section{Felipe Muanis}

Felipe Muanis é professor de cinema no Departamento de Comunicação Social da PUC-Rio. Foi coordenador do canal de TV universitária da PUC-Rio e trabalhou como diretor de arte em filmes e comerciais.

\section{Resumo}

A televisão, desde que foi inventada, passou por transformações na forma e no modo de percepção de seus espectadores. A palavra escrita, desde então, se ressentiu da maneira como a imagem se popularizou, gerando uma preocupação presente ainda nos dias de hoje, um antagonismo entre as letras e o audiovisual, mais especificamente à televisão. É importante, então, pensar qual é a inserção da televisão na formação de públicos. A questão do conteúdo é sempre discutida, mas passa a ser essencial a transformação do espectador comum, passivo, de homem-montador para montador cinematográfico, ativo, para que 0 antagonismo se resolva através da educação.

Palavras-chave: homem-montador, audiovisual, educação.

Uma imagem fala mais do que mil palavras. Agora experimente descrever imagem sem as palavras? Essa é uma forma de mostrar - quão difícil é trabalhar com a idéia de um embate entre imagem e texto e, especificamente, entre literatura e 
audiovisual. Discussão antiga que vem criando um certo sentimento de impotência na literatura frente a concorrência desleal das sedutoras imagens televisivas que, a cada dia, fazem diminuir o número de leitores, ou melhor, reduzir o número de possíveis amantes da leitura.

Discussão antiga em todos os sentidos: talvez hoje o grande concorrente, até maior que a televisão, sejam os videogames que afastam a criança e o jovem até da informação que também vem da televisão. Falar da televisão, portanto, está em uma região limítrofe entre o novo e o superado, entre o discurso de buscar um caminho de diálogo e entender como fazer dela, e das novas mídias audiovisuais, um aliado na educação e na formação de novos públicos letrados, ou de atacá-las como uma influência monstruosa e predatória diante da qual a solução seria, para muitos evitá-las. A intolerância e a incompreensão com alguns setores do audiovisual por parte de um segmento de intelectuais, inclusive de pensadores da comunicação, é, muitas vezes, conseqüência de pré-julgamentos, estabelecidos no senso comum e que nada ajudam para achar um caminho de confluência onde a televisão e, por exemplo, a literatura andem juntas e colaborem uma com a outra, gerando um público cada vez mais instruído e preparado. Para Henri Lefebvre,

Uma teoria nova não é jamais compreendida se se continua a julgála através de teorias antigas e de interpretações fundadas (à revelia daquele que reflete) sobre essas teorias antigas. (1)

Dentro dessa perspectiva talvez seja válido apontar um exemplo, antes de se chegar à televisão, de como o mundo das letras se ressente do mundo da imagem. Durante muito tempo as histórias em quadrinhos foram vilãs para uma elite cultural que as considerava divertimento fácil, subliteratura e até mesmo perigosas para a educação das crianças. Vários trabalhos citavam os quadrinhos como algo a ser evitado pelos pais e educadores, como se eles idiotizassem as crianças e ensinassem valores e posturas perigosas para a família. É notório o trabalho dos anos 50, A sedução do inocente, do psiquiatra Frederic Wertham, que acusa os quadrinhos de promovem a delinqüência juvenil, a alienação e o homossexualismo. A sociedade macarthista começa então a boicotar e queimar histórias em quadrinhos em praça pública e, com medo de uma intervenção do congresso americano, a indústria dos comics cria um selo de ética para colocar nas capas das revistas, uma espécie de aval para o seu conteúdo. Nada muito diferente da auto-regulamentação que a indústria do cinema criara, ainda no início do século, para evitar a intervenção do governo no lucrativo negócio. Com essa limitação várias histórias mudaram, a palavra crime não poderia aparecer na capa das revistas, não podia haver qualquer menção desonrosa aos agentes da lei e o bem sempre deveria vencer no final. As 
histórias de terror foram banidas e a indústria de quadrinhos americana, de fato, passou a ser mais inocente. Na Europa, no entanto, os quadrinhos gozavam de intensa liberdade criativa, abordando qualquer temática sem grandes problemas. Mesmo nos Estados Unidos, a contra-cultura, nos passos de Jack Kerouac e William Burroughs, construía o quadrinho underground com Robert Crumb e Gilbert Shelton que rompiam com o bem comportado, ocupando o espaço do confronto e da contestação.

Essa mídia, que se assemelha com o cinema, também está bem próxima da literatura, afinal os quadrinhos também se subdividem em gêneros: terror, ficção-científica, policial, underground, erótico, entre outros. Como o cinema e a literatura, o quadrinho também trabalha com a repetição e com a semelhança para referenciar seu espectador e gerar o seu consumo. Só que o diferencial da imagem é importante, com relação à literatura. Para a compreensão do receptor, nos quadrinhos, a letra não precisa se articular apenas com ela mesma já que a mensagem é uma junção feita, pelo leitor, a partir de uma associação principalmente entre desenho e texto. A imagem, sedutora no traço e na cor, facilita a fluência da mensagem, objetivando-a. Para alguns, mais do que isso, essa objetividade, essa construção física da imagem pelo desenho, empobreceria não só o texto como a capacidade de abstração do próprio leitor. Ele não precisaria mais construir a imagem a partir do texto, pois ela já estaria dada. Além disso, é possivel, nos quadrinhos, contar uma história apenas pela sucessão de imagens, através do enquadramento, da montagem e da condução da temporalidade, o que os aproxima muito da montagem cinematográfica, sem ser necessário qualquer uso da palavra.

A palavra, então, deixa de ser a única forma de ligação entre autor e leitor, de ser indispensável mas, ao mesmo tempo, estaria a salvo nas obras clássicas da literatura que não poderiam virar quadrinhos dada a sua complexidade textual. Ledo engano. Hoje vemos nas livrarias uma adaptação de Em busca do tempo perdido, de Proust, para os quadrinhos, e ainda há quem se espante. Na década de 80, a própria indústria de comics americana criou a série Classics Ilustrated com adaptações de clássicos da literatura como Moby Dick e o morro dos ventos uivantes. Já no Brasil, ainda na década de 40, a então recém inaugurada EBAL publicava a série Edição Maravilhosa com adaptações feitas por André Le Blanc, de romances clássicos brasileiros. Cinema e televisão também são profícuos em adaptações literárias e de folhetins atestando o caráter inequívoco da ligação entre a literatura e o audiovisual, nos diversos tempos, lugares e mídias. Mas independente do conteúdo, é importante entender como se relacionam palavra e imagem nas diversas mídias e o que representa a imagem, como linguagem, hoje: 
A cultura contemporânea é sobretudo visual. Videogames, videoclipes, cinema telenovela, propaganda e histórias em quadrinhos são técnicas de comunicação e de transmissão de cultura cuja força retórica reside sobretudo na imagem e secundariamente no texto escrito, que funciona mais como um complemento, muitas vezes até desnecessário, tal o impacto de significação dos recursos imagéticos.

Pensemos, por exemplo, nas narrativas visuais do cinema ou da telenovela, produtos culturais a que (quase) todos têm acesso e que competem diretamente com as narrativas literárias no gosto do público consumidor de cultura; o que se capta, em primeiro lugar, é um contexto demonstrativo em vez de um contexto verbal: percebe-se pela vestimenta, caracterização e comportamento das personagens, pelo lugar onde estão, por seus gestos e expressões faciais, se se trata de drama ou comédia, em que época se desenvolve o enredo, enfim, de que modo o espectador está sendo convidado a fruir aquele conjunto de significados visuais componentes de uma trama. Cada cena comporta um peso visual e auditivo, este dado pela trilha sonora, que se comunica imediatamente, sem necessidade de palavras. A imagem tem, portanto, seus próprios códigos de interação com o espectador, diversos daqueles que a palavra escrita estabelece com o seu leitor.(2).

Nesse sentido, cabe lembrar que o cinema, historicamente situado como baixa-cultura com relação à literatura, à rigor, não necessitava das palavras. De fato foi a chegada do som sincronizado que trouxe a possibilidade da palavra em cena, atrelando-se à montagem, através das falas do roteiro. É neste momento que a montagem passa a ficar presa à palavra. o cinema, que alcançava a liberdade modernista na experiência da vanguarda dos anos 20, rapidamente se conforma em um discurso diegético estruturado na palavra. Mas a força da imagem em oposição à palavra na mídia cinema ficou evidente mesmo nos filmes que construíam, através da montagem, uma poderosa estrutura semântica. Isso fica visível em clássicos do mudo, especificamente no trabalho de Pudovkin, Eisenstein e Abel Gance. O discernimento da montagem, pelo público, é mais simples e elementar do que da palavra, por isso facilmente reconhecível e legível(3). Vejamos: a experiência mnemônica do homem é composta por vários formas de percepção, inicialmente baseada nos sentidos, o olfato, o paladar, o tato, a imagem e que viriam a ser complementadas, posteriormente, pela própria linguagem. Pedi, recentemente, para um grupo de alunos relembrarem o que fizeram no dia anterior. Em seguida perguntei se, em seus pensamentos, suas memórias vinham através de imagens ou palavras. A resposta, praticamente uníssona, foi que rememoraram suas experiências através de imagens, ou seja, buscavam na memória, a partir do início do dia anterior, todo o percurso pelo qual passaram, para depois 
transformarem a lembrança em um código verbal representado por palavras e explicitarem suas experiências para a audiência.

Isso significa que somos todos montadores de imagem. Pensamos em imagens, pensamos em planos, fazemos enquadramentos e cortamos as imagens com 0 intuito de criar uma narrativa compreensível para nós mesmos. Este a quem chamo de o homemmontador, não um profissional cinematográfico, monta seqüências de imagens mentalmente para si. Como é o emissor e receptor da própria mensagem, não precisa seguir um código semântico rigoroso para ser claro na sua montagem, pois o reconhecimento da própria mensagem é imediato. Qual é a diferença para os montadores de cinema(4)? Os montadores de cinema exteriorizam essa montagem de modo a criar uma semântica lógica e compreensível para criar comunicação com seu interlocutor, elaborando a mensagem de modo que ela seja entendida pelo maior número possível de pessoas. O montador cinematográfico vai, então, entender $\bigcirc$ funcionamento da imagem, como ela é lida, qual seu significado, como relacionase junto às outras e tenta prever como ela é percebida pelo receptor. Neste momento ele está elaborando um código lingüístico representado por imagens, cortes, elipses, fusões, enquadramentos e movimentos, capazes de funcionar e comunicar não apenas para si próprio, como é como o homem-montador, mas capaz de ser reconhecido e lido por outras pessoas. A linguagem cinematográfica passa a existir de forma clara e precisa e, se quiser, sem depender da palavra para seu entendimento. O efeito dessa diferenciação entre o homemmontador e o montador-cinematográfico recai na capacidade que - homem tem em manipular conscientemente essas imagens, elaborando uma maior ou menor comunicação com o outro.

E como é o funcionamento com a imagem? Se o montador cinematográfico tem o domínio dessa linguagem, sabe manipulála a ponto de induzir sentimentos e emoções, o que cabe ao homem-montador? Por estar dentro de uma cultura específica e cada vez mais imagética, em função da mensagem dirigida a ele estar referenciada em signos, arquétipos, estereótipos e demarcações dessa mesma cultura, o homem-montador é um bom leitor. Ele entende o que lhe é apresentado. O nível dessa leitura já é outra questão: a capacidade de ler nas entrelinhas, de tirar mensagens diferentes e subliminares no texto que lhe é apresentado vai depender do quão imerso ele esteja na cultura e o quanto mais ele desenvolva o seu lado leitor desses códigos. Mas saberá ele escrever essa linguagem?

A experiência com alunos de publicidade já no final do curso é bastante elucidativa para tentar entender a diferença entre leitura e escritura da linguagem audiovisual. Sabe-se que a publicidade é uma carreira que pede uma bagagem de informação bastante grande, ainda que superficial, para poder gerar esses 
códigos e trabalhar esses estereótipos. Essa bagagem de informação está, nas novas gerações, referenciada principalmente na indústria cultural e no saber mundializado da cultura de massa: filmes blockbusters, séries de TV, desenhos animados, videoclipes, músicas, comerciais, imagens, marcas e produtos, revistas, livros, best-sellers, enfim, uma infinita gama de produtos que compõem esse universo cognitivo para que o maior número de pessoas, que detêm poder aquisitivo, possa consumir. Esses alunos, vivendo essa informação em seu cotidiano, costumam ter uma preferência pelos produtos audiovisuais que exprimem agilidade, rapidez, radicalidade, beleza e fruição, consumindo uma estética hedonista, como aponta Edgar Morin, que se constrói enormemente em função do incremento do aparato publicitário com base no fortalecimento, cada vez maior, da sociedade de consumo. O próprio zapping é, de certa forma, uma conseqüência disso, uma insatisfação com o eterno presente, uma fuga do passado, e a incessante busca pelo novo. Quando a maioria desses alunos vai escrever audiovisual - supõe-se que teria facilidade para isso, mas não tem. Cometem erros gramaticais graves, sem conseguir reproduzir a mesma agilidade dos produtos que admiram e gostam de consumir. Poderia facilmente justificar isso pela técnica ou pela ausência dela, pelo seu desconhecimento. Não é o caso. Mesmo nos exercícios realizados por esses alunos, nos quais simplesmente buscava-se pensar a imagem e a decupagem teoricamente, a montagem se estabelecia falha e sem o menor traço da radicalidade presente no gosto pessoal. Esse jovem, de classe-média alta e com acesso à informação, é um leitor bastante refinado, com capacidade de compreensão de construções imagéticas complexas - que hoje, por vezes, aproximam-se, na forma, ao hermetismo das antigas vanguardas - mas não consegue, muitas vezes, reproduzir esse discurso nem tampouco escrever um texto audiovisual básico, com alguma fluência narrativa. Existe, portanto, um hiato considerável entre o ler e o escrever, notório naquele em quem estou chamando de o homem-montador. E esse talvez seja o espaço para tentar solucionar o problema da escrita estar sendo eclipsada pela televisão.

Não há como negar o poder sedutor das imagens. Plasticamente construídas, apelam para todos os sentidos, com uma variedade de atrações e conteúdos em canais segmentados que permitem que - consumidor tenha um acesso fácil e rápido à várias realidades, situações e experiências, estéticas ou não. A televisão é o veículo ideal para essas construções e desde seu nascimento se mostrou com enorme capacidade de mudar hábitos e criar novos costumes. José Carlos Rodrigues(5), lembrando do surgimento da televisão em sua cidade, na década de 50, aponta como foi drástica a mudança comportamental que ali se operou. Enquanto que antes, durante a noite, os vizinhos se encontravam na rua para conversarem e as crianças brincarem, 
após o surgimento da televisão as ruas ficaram vazias e as pessoas reunidas dentro de casa, em torno dela. O encontro dos moradores agora se limitava ao que ele chama de "televizinho", ou seja, a pessoa que ia a casa mais próxima para ver televisão, pois não tinha tido ainda oportunidade de adquirir seu próprio aparelho. Como se vê, desde o início a televisão opera algum afastamento do lúdico, dos jogos e das brincadeiras. Por ser imagem a televisão fala à compreensão mais elementar do interlocutor, a de interpretar o que está vendo. A competição com a imagem, portanto, é bastante difícil, já que suas narrativas são extremamente sedutoras, trabalhadas pela forma, pela riqueza de informação, pela beleza e pela facilidade de absorção. Por ser narrativa flerta com a necessidade de ficção e referencial. Por ter conteúdo cria conhecimento, mas necessitando de um esforço, ou dedicação, diferente do utilizado na leitura de um livro. Esse esforço é um ponto importante: o ócio é necessário para o pensar, para o auto-conhecimento. O ritmo de vida imposto pela sociedade capitalista, de excesso de mão de obra e escassez de trabalho, aumenta a carga horária do trabalhador e se por um lado, compra uma melhor qualidade de vida, por outro diminui consideravelmente o tempo ocioso que ainda se divide nos afazeres domésticos e na família. Resta, assim, muito pouco para as solitárias atividades introspectivas. O descanso, por vezes, se dá através de uma necessidade narcotizante de se desligar da realidade estressante de forma fácil, despretensiosa e rápida. Nesse momento em que o pensar não é bem-vindo, ao invés do livro, liga-se a televisão. Esse pensar, que fique claro, não significa fugir de qualquer conteúdo que leve a um raciocínio mais refinado, mas sim não querer se esforçar muito em construir uma narrativa apenas parcialmente dada - e eventualmente não fechada - pelo autor da obra, seja em que meio for. O que acontece é uma mudança na forma de percepção de conteúdo na relação do espectador com o meio:

Depois da TV muitas coisas já não funcionam tão bem. Tanto o cinema como as revistas de âmbito nacional foram duramente golpeadas por esse novo meio. Até as histórias em quadrinhos declinaram bastante. Antes da TV, o fato de Joãozinho não ler causava muita preocupação; depois da TV, Joãozinho passou a dispor de todo um novo conjunto de percepções. Já não é o mesmo. Otto Preminger acha que o cinema americano amadureceu graças à influência da TV . O meio frio da TV incentiva a criação de estruturas de profundidade no mundo da arte e do entretenimento criando ao mesmo tempo um profundo envolvimento da audiência. (6)

Ao ligar a televisão com o que nos deparamos? Que tipo de programas vemos? Desde a televisão aberta, até a televisão por assinatura, encontramos a mais diversa programação de telejornais, shows, espetáculos, esportes, programas de auditório, seriados, enfim, uma variada gama que atende do mais ao menos exigente. Se é verdade que existem muitos 
programas abaixo da crítica, também existem programas inovadores de grande qualidade. Nessa questão da perda de espaço da literatura temos dois problemas distintos que necessitam ser diferenciados: a pessoa que troca um livro por um programa televisivo de má qualidade e a que troca o livro pela televisão, independente da atração, mas que a olha com um senso crítico mais apurado. A questão do programa de má qualidade me parece a mais simples: uma mistura de necessidade de ócio misturado a um referencial cultural mais estreito que impede o passeio por um leque mais amplo de canais, por outros programas ditos mais cultos ou refinados. O espelhamento entre espectador, ator e gênero, típico do star-system do cinema norte-americano, ressurge na questão do programa televisivo segmentado e da celebridade. Essa programação televisiva tem o caráter de passatempo, entretenimento fugaz, que na maior parte das vezes não colabora para o enriquecimento crítico do espectador. Já para o mais exigente, por outro lado, a busca pelo programa com conteúdo enriquecedor, por vezes, não difere da busca pelo de qualidade ruim, já que este último é visto com um olhar intencionalmente questionador. Para ele a televisão pode ser ou não concomitante ao livro, isto é, este espectador pode ser, boa parte das vezes, também um leitor que circunstancialmente fez a opção da televisão, mesmo tendo acesso e o hábito de ler. Essas situações e diferenças são determinantes, evidentemente, no processo de formação do espectador, ainda na idade escolar.

Segundo uma pesquisa publicada no jornal Folha de São Paulo(7), 57\% das crianças e adolescentes de 2 a 17 anos vêem, todo dia no Brasil, pelo menos três horas de televisão. Somente 5\% não vêem TV. O contra-ponto com o livro é assustador: 43\% das crianças não lêem livros em hora nenhuma no Brasil, o pior resultado entre os países analisados, enquanto que nos Estados Unidos 52\% lêem de uma a duas horas por dia e na China 45\% lêem a mesma quantidade:

Em contraponto à televisão, 43\% dos pais brasileiros ouvidos disseram que seus filhos não ocupam nada de seu tempo lendo livros ou brincando com os amigos; 79\% disseram que seus herdeiros não praticam esportes coletivos; 69\% afirmam que eles não usam computadores.o resultado é preocupante. Quando há mais TV do que leitura, há um empobrecimento do país. Não brincar também é perigoso. A criança que não brinca não conversa, fica isolada", diz Ana Bock, presidente eleita do Conselho Federal de Psicologia (CFP) e professora da PUC-SP. (8)

Como se vê, o lúdico está em baixa. A leitura ainda briga com outras mídias audiovisuais de apelo mais forte para as crianças, como o computador, neles contidos a internet e o videogame. Neste ponto é fundamental o exemplo e a educação dos pais, como complementa a matéria da Folha:

Carmona responsabiliza parcialmente a política educacional brasileira por esse panorama de muita televisão e pouca leitura e 
brincadeira. Mas não isenta a televisão. "A TV pode levar a criança a conclusões distorcidas. A TV mostra uma rua mais perigosa do que ela é, e isso gera medo, neurose, violência. A influência da televisão no Brasil é muito séria. Nossas crianças são mais desinformadas. Na Europa, há uma tradição de TV pública com programação para criança mais elaborada. (9)

Para Rodrigo Toni, diretor-geral do Ipsos no Brasil, a pesquisa não permite afirmar que a TV afasta a criança dos livros e das brincadeiras. "Há muita televisão, mas o que as afasta das outras atividades são a falta de hábito e os ambientes educacional e familiar. Os vilões são os próprios pais, que não valorizam a leitura", diz.

Opinião parecida tem a psicóloga especializada em famílias Lídia Aratangy:

Pais leitores têm mais chances de ter filhos leitores simplesmente porque as crianças percebem que aquele objeto deve ser muito importante para prender a atenção de uma pessoa tão importante. Ela recomenda também que os pais assistam à TV junto dos filhos, para transformá-los "de esponjas em filtros". (10)

Algumas questões aqui levantadas são importantes. Com o estado de insegurança que os habitantes dos grandes centros urbanos vivem em seu cotidiano, a criança não sai de casa com a facilidade de antes. Quando sai fica presa no próprio condomínio, fenômeno dos grandes centros urbanos, cada vez mais uma fortaleza ilhada de auto-suficiência. Brincar na rua, conhecer os vizinhos, jogar bola, conversar de noite sentado no meio-fio são características do passado. As crianças ficam em casa, onde estão seguras, e por vezes quem toma conta delas é a televisão, a "babá-eletrônica" como cita um pai durante a referida matéria. A sucessão rápida de imagens coloridas, diferentes, de mundos e realidades impossíveis, hedonistas, são sedutoras e hipnóticas para a criança. A babá-eletrônica não é apenas um artifício para que os pais possam descansar um pouco e, momentaneamente, se desligar do sentido de alerta com relação à segurança dos filhos. Ela é um grande problema porque não vem acompanhada do senso crítico que faria a criança, com o tempo, discernir o que é bom e o que é ruim. A solução é a apontada pela psicóloga, transformar as crianças de esponjas em filtros com o auxílio dos pais, que ajudariam a criar este senso crítico. Mas será isso suficiente? Como fazer para que a criança e até mesmo os pais desenvolvam essa capacidade? A resposta é fazer com que ambos deixem de ser um mero homem-montador para que passem a ser alfabetizados audiovisualmente, que entendam a gramática e a sintaxe da imagem para criar referenciais e terem uma maior possibilidade de fazer uma separação entre o programa bom e o ruim e, mais do que isso, entender o porquê de determinada programação ser prejudicial. Nesse sentido podemos rever a indignação de 
McLuhan com relação a restringir o problema da televisão apenas ao conteúdo:

Por não terem observado um aspecto tão fundamental da imagem da TV, os críticos da programação "conteudística" só têm falado bobagens a propósito da "violência na TV". Os porta-vozes do ponto de vista da censura são em geral indivíduos semiletrados, que se orientam pelos livros e que não conhecem a gramática do jornal, do rádio ou do cinema, tendendo a olhar torto para todos os meios não-livrescos. Uma pergunta das mais simples sobre um aspecto psíquico qualquer dos meios, incluindo o meio do livro, deixa essa gente tomada do pânico da incerteza. (11)

É importante a percepção que McLuhan faz das gramáticas dos outros meios. Atribuirmos a problemática somente ao conteúdo, como fazem alguns, significa nos isentarmos da própria responsabilidade que devemos ter para formar pessoas que detenham maior controle sobre o meio, seja como autor ou espectador. Então a idéia é que todos virássemos montadores cinematográficos? Precisamos dominar a forma? Talvez seja quase isso. Não de profissão, mas de raciocínio audiovisual. Estamos entrando em um momento de convergência de mídias onde a imagem nunca teve a importância que teve agora, seja pela difusão, seja pela proliferação de matrizes geradoras dessa imagem, amadoras ou institucionais. Se há cem anos, a imagem era feita por alguns poucos que tinham uma máquina fotográfica ou um cinematógrafo, hoje temos as câmeras de vídeo, das mais baratas às mais caras, bem como as câmeras de cinema e as câmeras fotográficas. Como se não bastasse, as câmeras começam a ser um artigo de cotidiano, presentes em telefones celulares, PDAs e até binóculos. Da mesma forma que o telefone celular que era um artigo de luxo há dez anos atrás foi barateando, se popularizando e acabou por virar o responsável pela democratização da telefonia no Brasil, esses aparelhos com câmeras embutidas serão responsáveis pela democratização da captação de imagens, um hábito cada vez mais corriqueiro. Não obstante isso, os computadores têm ficado cada vez mais potentes e com recursos de manipulação de imagens, estáticas e em movimento, que há dez anos atrás seriam impossíveis de serem feitas como são hoje, na casa das próprias pessoas. A profecia do cineasta George Lucas começa a se concretizar, a de que, em um futuro próximo, todas as pessoas poderiam fazer cinema na garagem da própria casa(12). E a divulgação desse material ainda pode ser feita pela internet nos blogs que se espalham pela rede.

Toda essa mudança que vem acontecendo nos últimos dez anos reforça uma necessidade que talvez passasse desapercebida anteriormente, a necessidade do ensino da linguagem audiovisual nas escolas. Hoje isso fica mais claro já que as pessoas estão, definitivamente, escrevendo com imagens. A caméra-stylo da nouvelle-vague virou uma realidade, só que de 
outra forma: a câmera está virando uma caneta no cotidiano das pessoas comuns. Para isso é necessário que saibam "escrever audiovisual", que tenham o discernimento dos seus referenciais, para poderem ser bons leitores. Mas qual é o problema para que isso aconteça? Com toda essa revolução da imagem acontecendo a cada dia que passa, alguns não se dão conta de que as antigas questões passam por novos prismas e de que discussões como essa, da literatura perder espaço para a televisão, tem que superar o mero discurso, seja apocalíptico ou integrado, e partir para uma visão mais pragmática e sintonizada com as novas demandas que surgem de uma dinâmica social diferente. Nesse ponto, a crítica que Haroldo de Campos faz a Benjamin é bastante adequada, mudando e invertendo os papéis para literatura e audiovisual:

Só no cinema reconhece Benjamin a elaboração de uma sintaxe peculiar, de uma nova linguagem comensurada aos novos tempos e capaz de "dar uma representação artística do real". Nisto sua visão é afetada de tradicionalismo, pois se recusa a admitir o que parece óbvio, isto é, que, paralelamente ao cinema e por sua vez sob o influxo dele, profundas alterações também se processaram nas outras artes, exigindo-lhes a reorganização dos respectivos sistemas de signos em moldes mais adequados à realidade da civilização técnica. (13)

É preciso que se reconheça a televisão também como uma sintaxe a ser estudada, para que entendamos melhor o audiovisual, as artes que a cercam e a influência sobre elas e o seu público. Um exemplo claro disso é a eterna discussão sobre adaptação literária para o cinema, onde a pergunta sobre o que é melhor, - livro ou o filme, é freqüente. O ponto de partida habitual é que o leitor lê o livro para depois ver o filme e fazer suas considerações. O que acontece muitas vezes atualmente, no entanto, é o contrário, o espectador vê o filme e essa experiência o leva ao livro. Esse movimento, inverso ao tradicional, é suficiente, como exemplo, para gerar uma série de discussões diferentes sobre a relação entre as obras escritas e audiovisuais. Adaptar-se a esse novo olhar é difícil, há uma resistência. Acostumou-se a olhar a produção cultural, historicamente, a partir do ponto de vista do que se considera alta-cultura para baixa-cultura. Sair desse, para outro olhar, é uma atitude necessária mas muito difícil para alguns. É como o episódio narrado por José Saramago no filme Janela da alma (João Jardim e Walter Carvalho, 2003). Em criança, o jovem Saramago ia ao teatro local e, do ponto de vista da platéia, admirava uma rica e enorme coroa que adornava o alto da boca de cena. Um dia, o jovem Saramago entra por dentro do palco, pelo ponto de vista oposto e repara que a coroa, por trás era feia, o oposto do que via do outro lado. A partir dali, disse ele, aprendeu que para ter uma visão melhor sobre algo, devia buscar olhá-la por todos os lados. 
Mas olhar de diferentes ângulos não é o que acontece. Como explicar que, em um país como o Brasil, onde a televisão tem um papel fundamental, e até exagerado, em nossa cultura, há pouca quantidade de estudos sobre este tema, que envolvam linguagem, produção, percepção? Vista do alto pelos próprios teóricos da comunicação, a televisão não estimula a produção intelectual e massa crítica compatível com o papel e importância que ela desempenha em nosso país. Arlindo Machado, Maria Rita Kehl, Eugênio Bucci, Mauro Alencar, entre outros, são dos poucos que perceberam que satanizar a televisão não é a solução para as transformações que a sociedade vive mas, ao contrário, entendê-la é o passaporte para construir uma televisão mais responsável e um espectador mais crítico. Como discutir a televisão se não a entendemos, se não sabemos dissecá-la? Como construir uma programação consistente se muitos professores, incluindo os da comunicação, consideram a análise televisiva algo menor? A televisão, frente a importância que tem no Brasil, deveria ser profundamente estudada. Só assim haveria uma produção crítica que formaria, com consistência, os profissionais que sairiam das universidades para fazer essa mesma televisão de modo diferente. O audiovisual já deu provas de que é possível existir produtos de qualidade como os infantis Castelo Rá-timBum e TV Colosso, fora os diversos filmes que são feitos e que são exibidos na televisão. As próprias TVs educativas e o Canal Futura, os programas que tem uma ligação inequívoca com a literatura como sítio do picapau amarelo e as adaptações de Guel Arraes, para o cinema e para a televisão, que misturam os mais diversos elementos e linguagens das diversas artes e mídias, revitalizam e atualizam os textos para as novas gerações e para os novos meios. Mais do que isso, a universidade ajudaria a formar o senso crítico dos futuros pais que, aí sim, poderiam ajudar as crianças, como foi dito, a serem filtros e não esponjas:

Henry-Jean Martin explica que, penetrados como estamos por uma cultura escrita, nossa imaginação não consegue ser suficientemente prodigiosa para compreender o mecanismo das culturas orais. "Parece, contudo - completa ele (14) - que, em nossa época, os novos meios de difusão não-escrita do pensamento, como são o cinema e sobretudo o rádio, deveriam ajudar-nos a conceber melhor - que pode ser, para milhões de indivíduos, uma transmissão de obras e de idéias que já não use o circuito normal do texto escrito." Levando em consideração próprio conceito de livro já discutido acima (instrumento para dar consistência ao pensamento disperso e para ampliar o seu poder de influência dentro de uma sociedade), não poderíamos, pois, dizer que os filmes, os vídeos, os discos e muitos programas de rádio e televisão são os "livros" de nosso tempo? (15)

Para que essa situação mude dentro da própria universidade, que é geradora e multiplicadora de conhecimento para a sociedade, a solução é, como sempre, o ensino fundamental. o 
ensino de duas matérias fundamentais para a criança voltar a ter o interesse pela leitura, mas também ter uma formação melhor perante as novas demandas sociais e desenvolvimentos midiáticos. O ensino de linguagem audiovisual acompanhado de filosofia nas escolas, faria com que as crianças desenvolvessem a capacidade de abstração ao mesmo tempo que seriam alfabetizadas nas letras e nas imagens, passando, com o tempo, a entender seus códigos, sua grafia, escrever e raciocinar com elas, inter-relacionando-as. O grande problema do homem-montador é que ele está diante de uma gramática sem percebê-la, ele a lê passivamente, sem fazer esforço:

Desde o momento que estamos diante da tela, não percebemos mais o texto enquanto texto, mas como imagem. Ora, escrever torna-se atividade plena na separação estrita do texto e da tela, do texto e da imagem - nunca uma interação.Da mesma forma, o espectador só se torna realmente ator quando há estrita separação entre palco e platéia. Tudo, porém, concorre, na atualidade, para a abolição desse corte: a imersão do espectador torna-se convival, interativa. Apogeu ou fim do espectador?

Extinguir, de certa forma, a ingenuidade desse homem, é a possibilidade não apenas da construção de um saber importante para a sociedade atual, mas também de desenvolver nele um raciocínio constante diante de uma linguagem com a qual, hoje, se tem um contato apenas passivo. Com o tempo os programas de televisão melhorariam, provavelmente seriam menos danosos e haveria uma maior integração entre o audiovisual e as letras, uma colaborando com o entendimento da outra. A ditadura da imagem, que a literatura sente com relação a televisão de hoje em dia, não é diferente do domínio que a escrita tinha na Idade Média que, sendo saber de poucos, era usado como instrumento de poder. Hoje é o mesmo com as imagens. Resta saber se a solução é jogar a televisão na fogueira ou, para que todos sobrevivam, amplie-se a consciência, mude-se o discurso secular e democratize-se de verdade o escrever audiovisual.

\section{Abstract}

The television, since that it was invented, it passed for hashings in the form and the mode of perception of the audience. The written word, since then, if resented in the way as the picture was popularized generating, still nowadays, an antagonism between the words and the audiovisual, more specifically to the television. It is important, then, to think which is the insertion of the television in the audience development. The content is always pointed but it starts to be essential the hashing of the common spectator, of "editing-man" for a cinematographic one, an active assembler. By this way, the antagonism can be solved by education.

Key-Words: editing-man, audiovisual, education. 


\section{Notas}

(1) Apud ANDRADE 2000, p. 19

(2) PELLEGRINI, 2003, p. 15, 16.

(3) Parto do princípio que tento a palavra quanto a imagem são constituídos, através da literatura e do cinema, respectivamente, como códigos criados com o objetivo final de comunicar algo ao seu interlocutor.

(4) A transição que faço através do cinema é em função dele continuar sendo a referência, no campo teórico, para os estudos no campo audiovisual. As outras mídias audiovisuais têm as suas bases na linguagem cinematográfica que tem na montagem, o seu elemento de distinção das outras artes.

(5) Refiro-me ao Professor José Carlos Rodrigues, autor do livro Antropologia e comunicação - princípios radicais, em aula no curso de pósgraduação em Comunicação Social da PUC-Rio, em setembro de 2003.

(6) MCLUHAN, 2003, p. 350.

(7) Folha Ilustrada, 17 de outubro de 2004. Fonte da pesquisa, Instituto Ipsos. "Pesquisa feita em dez países (Brasil, México, EUA, Canadá, França, Alemanha, Itália, Espanha, Reino Unido e China) entre novembro e dezembro de 2003. Foram ouvidos 500 pais de crianças e adolescentes de 2 a 17 anos em cada pais, exceto nos EUA, onde foram entrevistadas mil pessoas. No Brasil, México e China a pesquisa foi feita apenas em centros urbanos. A margem de erro é de quatro pontos, exceto nos EUA (três pontos).

(8) CASTRO, 2004, p. 1.

(9) Ibidem CASTRO, 2004, p. 1.

(10) Ibidem CASTRO, 2004, p. 1.

(11) MCLUHAN, 2003, p. 353.

(12) WIRED, fevereiro de 1997, p. 212.

(13) Apud ANDRADE, 2000, p. 27.

(14) MARTIN 1992, p. 33.

(15) MARTIN 1992, p. 33.

(16) BAUDRILLARD， 1997, p. 146.

\section{Bibliografia}

ANDRADE, Oswald de. Pau-Brasil. São Paulo: Globo, 2000.

BAUDRILLARD, Jean. Tela total: mito-ironias da era do virtual e da imagem. Porto Alegre: Sulina, 1997.

BUCCI, Eugênio, KEHL, Maria Rita. Videologias. São Paulo: Boitempo, 2004. 
Txt: Leituras Transdisciplinares de Telas e Textos, Belo Horizonte, v.1, n.1, p.7-21, 2005

CASTRO, Daniel. Superligados na TV. Folha de São Paulo, São Paulo, 17 out. 2004. Folha Ilustrada, p.1.

KELLY, Kevin, PARISI, Paula. Beyond Star Wars: what's next for George Lucas. Wired. Feb. 1997.

MACHADO, Arlindo. A televisão levada a sério. São Paulo: Senac, 2000.

MACHADO, Arlindo. Pré-cinemas \& pós-cinemas. São Paulo: Papirus, 2002.

MC LUHAN, Marshall. Os meios de comunicação como extensões do homem. São Paulo: Cultrix, 2003.

PELLEGRINI, Tânia (et al.). Literatura, cinema e televisão. São Paulo: Senac, 2003. 